\section{Intracellular distribution of Tankyrases as detected by multicolor immunofluorescence techniques}

\author{
M.G. Bottone, ${ }^{1,2}$ G. Santin, ${ }^{2}$ C. Soldani, ${ }^{1}$ \\ P. Veneroni, ${ }^{1}$ C. Alpini, ${ }^{3}$ A.I. Scovassi ${ }^{2}$ \\ 'Dipartimento di Biologia Animale, \\ Università di Pavia; \\ 2Istituto di Genetica Molecolare CNR, \\ Pavia; \\ ${ }^{3}$ Laboratorio di Analisi Biochimico- \\ Cliniche, IRCCS San Matteo, Pavia, Italy
}

\begin{abstract}
Poly(ADP-ribose) polymerases are a family of enzymes that catalyze the conversion of $\mathrm{NAD}^{+}$into ADP-ribose. Among them, Tankyrases have been found to bind to centrosome, mitotic spindle and microsome proteins, in the cytoplasm, and to telomeres in analysis of their level and localization could be instrumental to investigate their possible roles in cancer cells. The aim of the present work was to apply multicolor immunofluorescence protocols to detect the intracellular distribution of Tanks. Moreover, we addressed for the first time their dynamic relocation during apoptosis.
\end{abstract} the nucleus, where they play a relevant role in telomere metabolism. However, their precise intracellular localization during interphase has not been so far fully elucidated. We investigated this aspect in situ by double immunofluorescence experiments using antibodies recognizing Tankyrases 1-2 or other proteins residing in specific organelles (Golgi apparatus, mitochondria, lysosomes, endoplasmic reticulum). We used HeLa cells as a model system in vitro, before and after treatment with either actinomycin D or etoposide, to also investigate the possible relocation of Tankyrases during apoptosis. We observed that Tankyrases are distributed both in the nucleus and in the cytoplasm; in this latter compartment, they were found to colocate with the Golgi apparatus but never with the mitochondria; a pool of Tankyrases also colocates with the endoplasmic reticulum and lysosomes. Interestingly, in cells with clear signs of apoptosis, Tankyrases were detectable in the cytoplasmic blebs: this suggests that they are not massively cleaved during apoptosis and persist in the largely heterogeneous apoptotic remnants which are known to contain components of cytoplasmic and nuclear origin.

\section{Introduction}

Tankyrases (Tanks) 1 and 2 belong to the poly(ADP-ribosylation) family enzymes ${ }^{1,2}$ and are soluble proteins that can bind to cytoskeletal, microsome and cytosolic pro- teins. ${ }^{3,4}$ A small fraction of Tank 1 is localized at telomeres, where it regulates the accessibility of telomeric DNA to telomerase. ${ }^{5}$ Tank 1 is required for proper assembly of a bipolar spindle, but not for spindle poles themselves. ${ }^{6}$ The majority of non-telomeric Tanks reside in the cytosol at multiple loci including centrosomes, Golgi complexes and nuclear pore. ${ }^{7,8}$ Given their association to membrane bound organelles, Tanks could have additional non-nuclear functions as scaffolding proteins regulating the formation of large protein networks in the cytoplasm. ${ }^{9}$ Our knowledge on Tank subcellular localization is still fragmentary. Taking into account that the expression of these proteins is upregulated in a variety of cancers, ${ }^{10-13}$ the

\section{Materials and Methods}

\section{Cell culture and treatments}

Human HeLa cells (ATCC, Rockville, MD, USA) were grown in $75 \mathrm{~cm}^{2}$ flasks in Dulbecco's modified Eagle's medium (DMEM) supplemented with $10 \%$ fetal bovine serum, $1 \%$ glutamine, $100 \mathrm{U}$ of penicillin and streptomycin (Celbio, Pero, Italy) in $5 \% \mathrm{CO}_{2}$ humidified atmosphere. Twenty-four hours before the experiments, cells were seeded on glass coverslips and processed for immunofluorescence microscopy.

In order to induce apoptosis, the cells were incubated with either $100 \mu \mathrm{M}$ etoposide or 1 $\mu \mathrm{g} / \mathrm{mL}$ actinomycin D for $20 \mathrm{~h}$. After the treatments, the samples were fixed with $4 \%$ formalin formalin for $30 \mathrm{~min}$ at $4^{\circ} \mathrm{C}$ and post fixed with $70 \%$ ethanol for $24 \mathrm{~h}$ at $-20^{\circ} \mathrm{C}$.

\section{Indirect immunofluorescence}

Samples were rehydrated for $15 \mathrm{~min}$ in PBS and then immunolabeled with the antibodies listed in Table 1. All the incubations were performed at room temperature for $1 \mathrm{~h}$. Cells were then counterstained for DNA with $0.1 \mu \mathrm{g} / \mathrm{mL}$ of Hoechst 33258 (Sigma-Aldrich, Milano, Italy) for $10 \mathrm{~min}$, washed with PBS, and mounted in a drop of Mowiol (Calbiochem-Inalco, Milano, Italy) for confocal microscopy.
Correspondence: Dr. Anna Ivana Scovassi, Istituto di Genetica Molecolare CNR, via Abbiategrasso 207, 27100 Pavia, Italy.

Tel. +39.0382 .546334 - Fax +39.0382 .422286 .

E-mail: scovassi@igm.cnr.it

Key words: apoptosis, confocal microscopy, immunocytochemistry, organelles, PARP, Tankyrases.

Acknowledgements: the authors are grateful to Dr. Patrizia Vaghi, Centro Grandi Strumenti, University of Pavia, for confocal images. This work was supported by the University of Pavia (Fondo di Ateneo per la Ricerca 2010). SG is supported by the Superpig Program (Funds for Promoting Institutional Agreements, Regione Lombardia, Italy).

Contributions: GS, CS, PV, CA, execution of experiments; MGB, AIS, design of experiments and manuscript writing.

Received for publication: 3 November 2011. Accepted for publication: 24 November 2011.

This work is licensed under a Creative Commons Attribution NonCommercial 3.0 License (CC BYNC 3.0).

(C) Copyright M.G. Bottone et al., 2012

Licensee PAGEPress, Italy

European Journal of Histochemistry 2012; 56:e4 doi:10.4081/ejh.2012.e4

\section{Confocal fluorescence microscopy}

Confocal laser scanning microscopy was performed with a Leica TCS-SP system mounted on a Leica DMIRBE inverted microscope. For fluorescence excitation, an Ar UV laser at $364 \mathrm{~nm}$ was used for Hoechst 33258 , Ar visible laser at $488 \mathrm{~nm}$ for Alexa 488 , and $\mathrm{He} / \mathrm{Ne}$ laser at 543 for Alexa 594. Spaced (0.5 $\mu \mathrm{m})$ optical sections were recorded using a $63 \mathrm{X}$ oil immersion objective. Images were collected in the $1024 \times 1024$-pixel format, stored on a magnetic mass memory, and processed by the Leica confocal software.

\section{Results and Discussion}

The intracellular distribution of Tanks and microfilaments has been investigated by multicolor immunofluorescence experiments simultaneously using an antibody recognizing Tanks 1-2, Alexa 488-conjugated phalloidin, and a final staining of nuclear DNA with Hoechst 33258 (blue fluorescence). In control HeLa cells, which displayed the typical pattern of the microfilament network (green fluorescence), Tank labeling (red flu- 
Table 1. Primary and secondary antibodies used for multicolor immunofluorescence experiments.

\begin{tabular}{|c|c|c|c|}
\hline Antigen & Primary antibody & $\begin{array}{l}\text { Dilution } \\
\text { (in PBS) }\end{array}$ & $\begin{array}{l}\text { Secondary antibody } \\
\text { (1:200 in PBS) }\end{array}$ \\
\hline Tankyrases 1-2 & Monoclonal antibody (Alexis) & $1: 20$ & $\begin{array}{l}\text { Alexa 594-conjugated anti-rabbit IgG } \\
\text { (Molecular Probes, Invitrogen) }\end{array}$ \\
\hline Mitochondria & $\begin{array}{l}\text { Human autoimmune serum recognizing } \\
\text { mitochondrial pyruvate dehydrogenase }\end{array}$ & $1: 200$ & $\begin{array}{l}\text { Alexa 488-conjugated anti-human IgG } \\
\text { (Molecular Probes) }\end{array}$ \\
\hline Golgi apparatus & $\begin{array}{l}\text { Human autoimmune serum recognizing proteins } \\
\text { of Golgi apparatus }{ }^{15}\end{array}$ & $1: 250$ & $\begin{array}{l}\text { Alexa 488-conjugated anti-human IgG } \\
\text { (Molecular Probes) }\end{array}$ \\
\hline Lysosomes & $\begin{array}{l}\text { Human autoimmune serum recognizing lysosomal } \\
\text { proteins (IRCCS San Matteo, Pavia, Italy) }\end{array}$ & $1: 200$ & $\begin{array}{l}\text { Alexa 488-conjugated anti-human IgG } \\
\text { (Molecular Probes) }\end{array}$ \\
\hline Endoplasmic reticulum & $\begin{array}{l}\text { Human autoimmune serum recognizing } \\
\text { endoplasmic reticulum proteins }{ }^{16}\end{array}$ & $1: 200$ & $\begin{array}{l}\text { Alexa 488-conjugated anti-human IgG } \\
\text { (Molecular Probes) }\end{array}$ \\
\hline Microfilaments & Alexa 488-conjugated phalloidin & $1: 40$ & Molecular Probes \\
\hline
\end{tabular}

orescence) was mainly confined to the cytoplasm, with few spots within the nucleus (Figure 1a).

To address the destiny of Tanks during apoptosis, HeLa cells were incubated with two known apoptogenic drugs, ${ }^{17}$ i.e. etoposide (Figure 1b) and actinomycin D (Figure 1c). Hoechst staining confirmed that cells were undergoing apoptosis, with clear signs of nuclear condensation and chromatin fragmentation (Figure 1b,c); moreover, apoptotic cells proved to reorganize their cytoskeleton, with fragmentation of the microfilament bundles and the positivity for phalloidin mainly confined to the peripheral cytoplasmic region (Figure 1b,c; green fluorescence). Tanks 1-2 distribution in early apoptotic cells was essentially restricted to the perinuclear cytoplasmic region (Figure 1b,c; red fluorescence). In the advanced steps of the apoptotic process, HeLa cells showed the typical chromatin fragmentation and membrane blebbing (Figure 1b,c; arrows), characterized by the presence of Tanks within the blebs. This observation indicates that during apoptosis Tanks aggregate in the form of large spots and become components of the protein complexes that are released at the cell surface in the late apoptotic steps. ${ }^{18,19}$

To better explore the cytoplasmic distribution of Tanks, we performed an accurate analysis of their possible colocalization with some organelles, i.e. Golgi apparatus, mitochondria, endoplasmic reticulum and lysosomes. Figure 2 shows the double immunofluorescence analysis of Tanks (red fluorescence) and the mitochondrial pyruvate dehydrogenase (green fluorescence). As expected, normal HeLa cells (panel a) showed a cytoplasmic staining for mitochondria (green fluorescence) that never overlaps with Tank labeling (red fluorescence). In fact, confocal microscopy fluorescence curves shown in panels a', a" of Figure 2, confirmed that Tanks are not resident mitochondrial proteins. In apoptotic cells (panel b), mitochon-
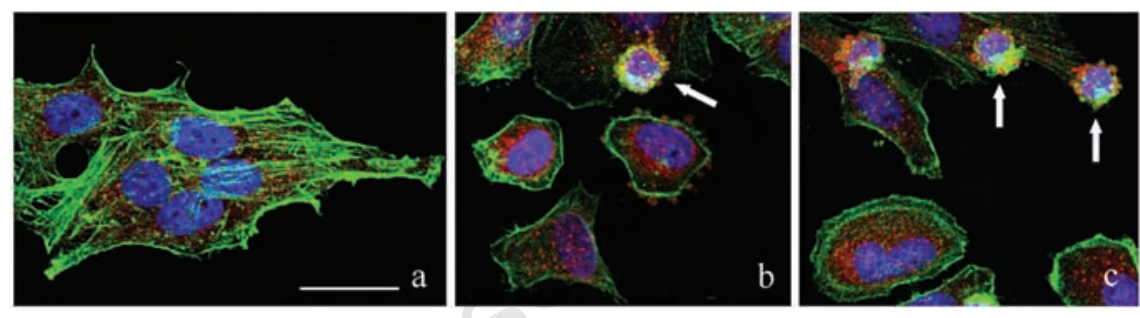

Figure 1. Confocal images of HeLa cells after immunolabeling for Tanks 1-2 (red fluorescence) and microfilaments (green fluorescence): a) control cells; b) cells treated with $100 \mu \mathrm{M}$ etoposide for $20 \mathrm{~h}$; c) cells treated with $1 \mu \mathrm{g} / \mathrm{mL}$ actinomycin D for $20 \mathrm{~h}$. Arrows in b, c: apoptotic cells. DNA was stained with Hoechst 33258 (blue fluorescence). Scale bar: $20 \mu \mathrm{m}$.
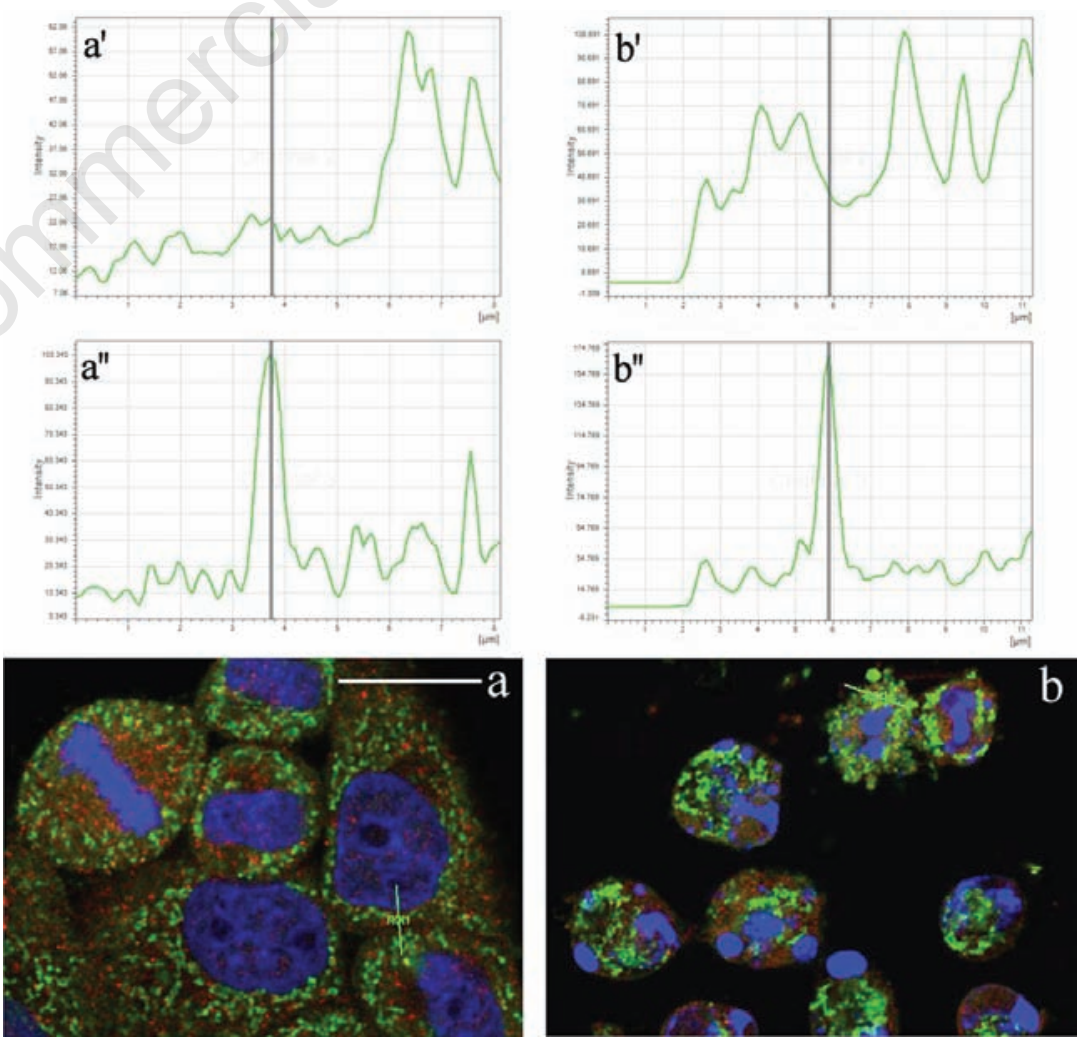

Figure 2. Confocal optical sections after immunolabeling for Tanks (red fluorescence) and mitochondria (green fluorescence): a) control HeLa cells; b) cells treated with $100 \mu \mathrm{M}$ etoposide for $20 \mathrm{~h}$. DNA was counterstained with Hoechst 33258 (blue fluorescence). Lines in a, $b$ represent the region where fusion of green/red fluorescence was measured. Upper $\left(\mathbf{a}^{\prime}, \mathbf{b}^{\prime}\right)$ and lower (a",b”) panels refer to green and red fluorescence, respectively. Scale bar: $20 \mu \mathrm{m}$. 
dria appeared to be condensed, and form large aggregates within the cytoplasm; in this condition too, Tanks never colocalized with mitochondria (Figure 2b',b").

The double immunofluorescence analysis for Tanks and Golgi proteins revealed that both antigens colocalize in control HeLa cells (Figure 3a',a") as well as in early (Figure 3b, arrow) and late (Figure 3b, asterisk) apoptotic cells, where Tanks and Golgi proteins were observed within apoptotic blebs (Figure 3b',b": early apoptosis; Figure 3b"',b"': late apoptosis).

Figure 4 shows non-apoptotic (a) and apoptotic (b) HeLa cells probed for Tanks (red fluorescence) and the endoplasmic reticulum (green fluorescence). In both samples, the colocalization of Tanks and the endoplasmic proteins was visible, even within apoptotic blebs (Figure 4a',a"; Figure $4 \mathrm{~b}$ ',b"). Finally, we found that a pool of Tanks colocates with lysosomal proteins in control cells (Figure 5a,a',a"). Remarkably, during apoptosis (Figure $5 \mathrm{~b}$ ) there was a size reduction and aggregation of lysosomes in the cytoplasm, and only a fraction of lysosomes appeared to be labeled for Tanks (Figure $5 b$,b").

Our results increase the knowledge on the intracellular localization of Tanks. More precisely, we focused on the protein fraction resident within the cytoplasm, which was so far less investigated. We demonstrated for the first time that Tanks 1-2 (or different pools of these proteins) not only associate with Golgi apparatus, as already shown, ${ }^{8}$ but also with other organelles, i.e. endoplasmic reticulum and lysosomes, which all belong to the vacuolar structure of the cells. In this respect, the evidence that Tanks do not colocate with mitochondria is not surprising.

The observation that Tanks can be detected within apoptotic blebs is also original and novel, and suggests that these proteins do not undergo complete proteolytic cleavage during apoptosis. Thus, Tanks represent additional constituents of apoptotic blebs which are known to contain a plethora of heterogeneous cytoplasmic and nuclear aggregates of proteins and nucleic acids to be extruded from the dying cell, ${ }^{19,20}$ including another member of the poly(ADP-ribose) polymerase family, PARP-1. ${ }^{21,22}$

Taking into account that similar results have been obtained in HeLa cells driven to apoptosis with either etoposide or actinomycin D (i.e., with drugs that induce apoptosis through completely different mechanisms), it is tempting to speculate that our observations may reflect a general phenomenon; this point needs however to be confirmed by further analyses performed on other cell lines.
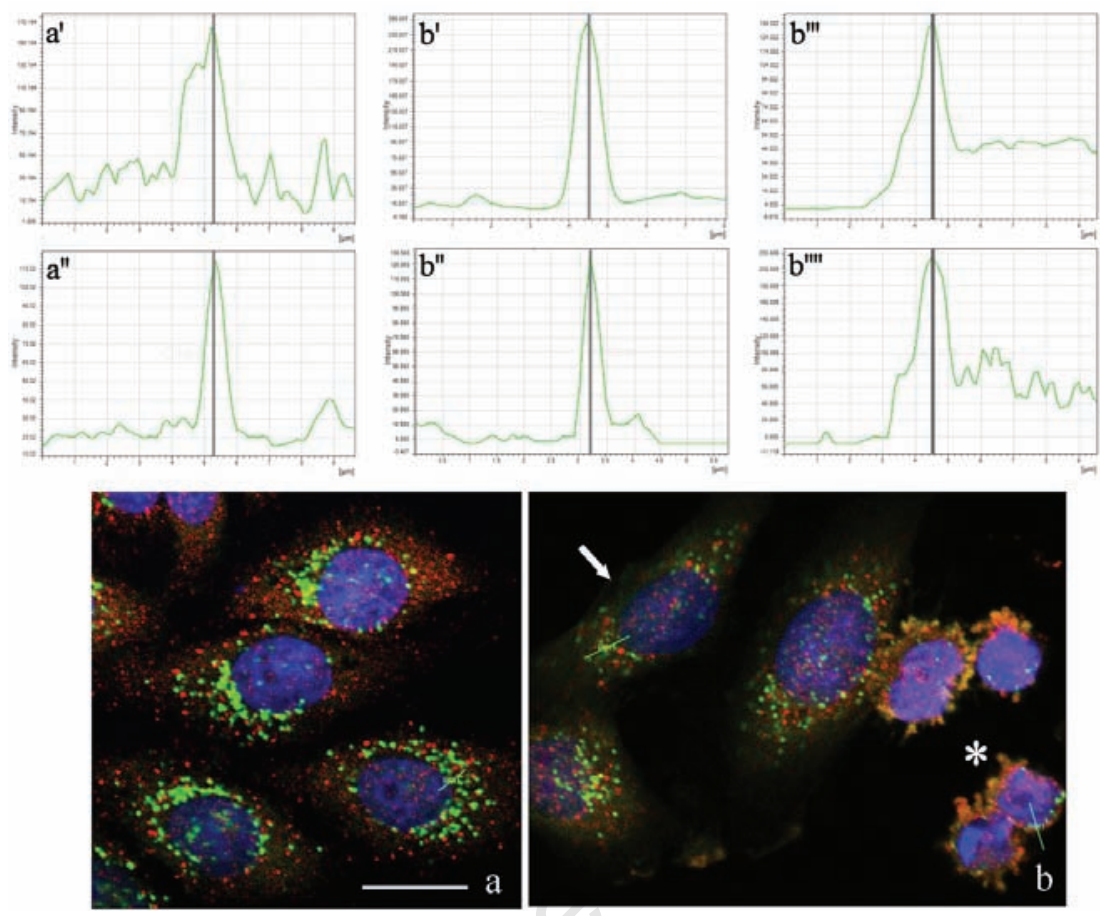

Figure 3. Confocal optical sections after immunolabeling for Tanks (red fluorescence) and Golgi apparatus (green fluorescence): a) control HeLa cells; b) cells driven to apoptosis by a treatment with $100 \mu \mathrm{M}$ etoposide for $20 \mathrm{~h}$ (arrow: early; asterisk: late apoptotic cells). DNA was counterstained with Hoechst 33258 (blue fluorescence). Lines in a and $b$ represent the region where fusion of green/red fluorescence was measured. Upper $\left(a^{\prime}, b^{\prime}, b^{\prime \prime}\right)$ and lower (a",b",b"') panels refer to green and red fluorescence, respectively. Scale bar: $20 \mu \mathrm{m}$.

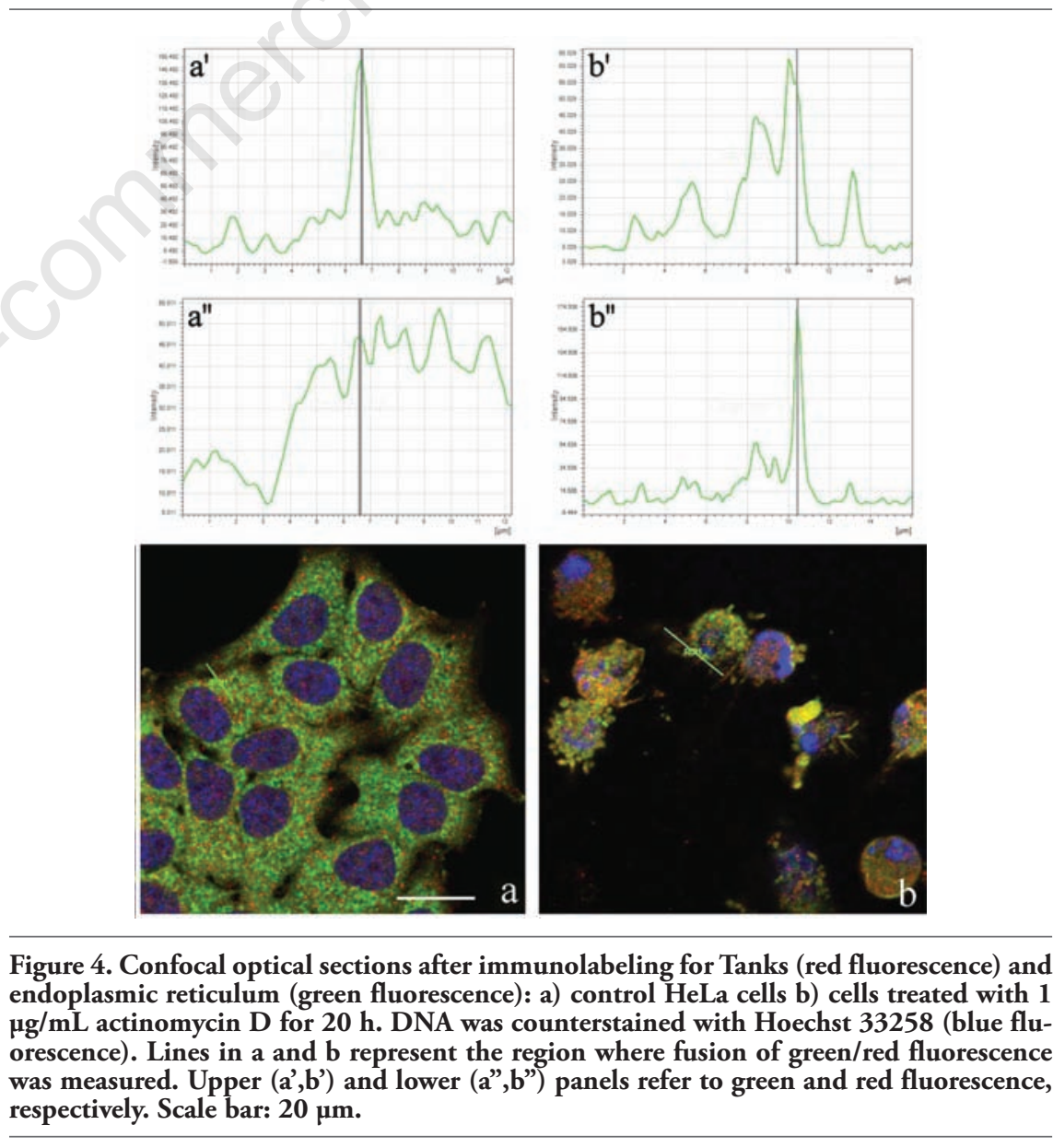



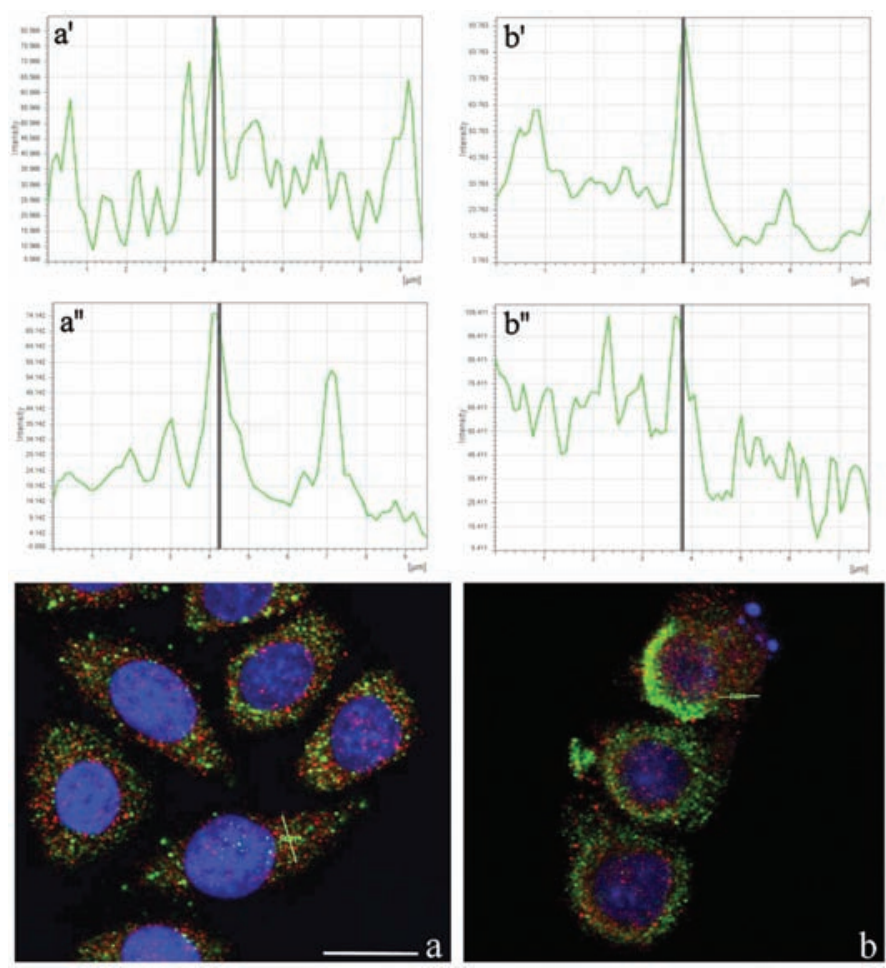

Figure 5. Confocal optical sections after immunolabeling for Tanks (red fluorescence) and lysosomes (green fluorescence): a) control; b) HeLa cells after treatment with $1 \mathrm{\mu g} / \mathrm{mL}$ actinomycin D for $20 \mathrm{~h}$. DNA was counterstained with Hoechst 33258 (blue fluorescence). Lines in $\mathbf{a}, \mathrm{b}$ represent the region where fusion of green/red fluorescence was measured. Upper $\left(a^{\prime}, b^{\prime}\right)$ and lower $\left(a^{\prime \prime}, b^{\prime \prime}\right)$ panels refer to green and red fluorescence, respectively. Scale bar: $20 \mu \mathrm{m}$.

\section{References}

1. Giansanti V, Donà F, Scovassi AI. Poly(ADP-ribosylation): Beneficial effects of its inhibition. Curr Enz Inhib 2009;5:99109.

2. Giansanti V, Donà $\mathrm{F}$, Tillhon $\mathrm{M}$, Scovassi AI. PARP inhibitors: new tools to protect from inflammation. Biochem Pharmacol 2010;80:1869-77.

3. Kuimov AN, Terekhov SM. Soluble tankyrase located in cytosol of human embryonic kidney cell line 293. Biochemistry (Moscow) 2003;68:260-8.

4. Hsiao SJ, Smith S. Tankyrase function at telomeres, spindle poles, and beyond. Biochimie 2008;90:83-92.

5. Donà F, Mondello C, Scovassi AI. Poly(ADPribosylation) at telomeres. Trends Cell Mol Biol 2007;2:77-88.

6. Chang P, Coughlin M, Mitchison TJ. Tankyrase-1 polymerization of poly(ADPribose) is required for spindle structure and function. Nat Cell Biol 2005;7:11331139.
7. Smith S, de Lange T. Cell cycle dependent localization of the telomeric PARP, tankyrase, to nuclear pore complexes and centrosomes J Cell Sci 1999;112:3649-56.

8. Chi NW, Lodish HF. Tankyrase is a Golgiassociated mitogen-activated protein kinase substrate that interacts with IRAP in GLUT4 vesicles. J Biol Chem 2000;275: 38437-44.

9. Hatsugai K, Ohishi T, Sugimoto Y, Seimiya H. Tankyrase-1 assembly to large protein complexes blocks its telomeric function. FEBS Lett 2010;584:3885-90.

10. Gelmini S, Poggesi M, Distante V Bianchi S, Simi L, Luconi M, et al. Tankyrase, a positive regulator of telomere elongation, is over expressed in human breast cancer. Cancer Lett 2004;216:81-7.

11. Gelmini S, Poggesi M, Pinzani P, Mannurita SC, Cianchi F, Valanzano R, et al. Distribution of Tankyrase-1 mRNA expression in colon cancer and its prospective correlation with progression stage. Oncol Rep 2006;16:1261-6.

12. Gelmini S, Quattrone S, Malentacchi F, Villari D, Travaglini F, Giannarini G, et al.
Tankyrase-1 mRNA expression in bladder cancer and paired urine sediment: preliminary experience. Clin Chem Lab Med 2007;45:862-6.

13. Gao J, Zhang J, Long Y, Tian Y, Lu X. Expression of tankyrase 1 in gastric cancer and its correlation with telomerase activity. Pathol Oncol Res 2011;17:685-90.

14. Bottone MG, Soldani C, Veneroni P, Avella D, Pisu M, Bernocchi G. Cell proliferation, apoptosis and mitochondrial damage in rat B50 neuronal cells after cisplatin treatment. Cell Prolif 2008;41:506-20.

15. Soldani C, Bottone MG, Croce AC, Fraschini A, Bottiroli G, Pellicciari C. The Golgi apparatus is a primary site of intracellular damage after photosensitization with Rose Bengal acetate. Eur J Histochem 2004;48:443-8.

16. Santin G, Piccolini VM, Veneroni P, Barni S, Bernocchi G, Bottone MG. Different patterns of apoptosis in response to cisplatin in B50 neuroblastoma rat cells. Histol Histopathol 2011;26:831-42.

17. Scovassi AI, Bottone MG, Biggiogera M, Pellicciari C. Dynamic relocation of nuclear proteins during the execution phase of apoptosis. Biochem Pharmacol 2008;76:1440-50.

18. Biggiogera M, Bottone MG, Scovassi AI, Soldani C, Vecchio L, Pellicciari C. Rearrangement of nuclear ribonucleoprotein (RNP)-containing structures during apoptosis and transcriptional arrest. Biol Cell 2004;96:603-15.

19. Pellicciari C, Bottone MG, Soldani C, Vecchio L, Biggiogera M. Extrusion of nuclear proteins during apoptosis. In: AI Scovassi (ed.) Apoptosis. 2005, Research Signpost, Trivandrum, India, pp. 131-44.

20. Soldani C, Bottone MG, Pellicciari C, Scovassi AI. Nucleolus disassembly in mitosis and apoptosis: dynamic redistribution of phosphorylated-c-Myc, fibrillarin and Ki-67. Eur J Histochem 2006;50:257-4.

21. Soldani C, Lazzè MC, Bottone MG, Tognon G, Biggiogera M, Pellicciari C, et al. Poly(ADP-ribose) polymerase cleavage during apoptosis: when and where? Exp Cell Res 2001;269:193-201.

22. Perdoni F, Bottone MG, Soldani C, Veneroni P, Alpini C, Pellicciari C, et al. Distribution of centromeric proteins and PARP-1 during mitosis and apoptosis. Ann N Y Acad Sci 2009;1171:32-7. 